ICRDET-2021, February 26-27, 2021, AICE, Jaipur, India

International Journal of Technical Research \& Science (Special Issue) ISSN No.:2454-2024 (online)

\title{
AUTOMATED THERMAL SCREENING DOOR
}

\author{
Hemlata Panwar, Raksha, Gajendra Singh Shekawat \\ E-Mail Id: hemlata.panwar@anandice.ac.in \\ Department of Electronics \& Communication Engineering, Anand International College of Engineering \\ Jaipur, India
}

Abstract- Nowadays, everyone prefer thermal screening test to protect against corona, whenever you go inside the mall, multiplex, supermarkets, railway stations, airports, and various other places before granting access to the visitors. You need a human for that thermal screening test at the entrance, then this automatic door will not require that person, it will automatically go to thermal screening whenever, In this every human will have to bring his/her hand forward and put it in front of the sensor, then there will be display a temperature on the screen, then it will show the temperature under controlled or not. The MLX90614 is a high- performance Infrared Temperature Sensor that can be used to automatically make a temperature check-up and decide whether to grant the door access. The body temperature is under controlled when the door will open automatically it shows green light and the door will not open when the body temperature is out of range it shows red light.

Keywords- Infrared Temperature Sensor.

\section{INTRODUCTION}

We have presented a automated thermal screening door for monitoring the temperature of human when they passed through the gate. If temperature of a person is more than 99 degree Fahrenheit then the gate automatically rejects the entry (by closing it). The gate also provides warning beeps if the temperature is high.

We need a human for that thermal screening test at the entrance, then this automatic door will not require that person, it will automatically go to thermal screening whenever, In this every human will have to bring his/her hand forward and put it in front of the sensor, then there will be display a temperature on the screen, then it will show the temperature under controlled or not. The MLX90614 is an infrared thermometer for non-contact temperature measurements. Both the IR sensitive thermopile detector chip and the signal conditioning ASIC are integrated in the same TO-39 can. Integrated into the MLX90614 are a low noise amplifier, 17-bit ADC and powerful DSP unit thus achieving high accuracy and resolution of the thermometer.

The thermometer comes factory calibrated with a digital SMBus output giving full access to the measured temperature in the complete temperature range(s) with a resolution of $0.02^{\circ} \mathrm{C}$. The user can configure the digital output to be pulse width modulation (PWM). As a standard, the 10-bit PWM is configured to continuously transmit the measured temperature in range of -20 to $120^{\circ} \mathrm{C}$, with an output resolution of $0.14^{\circ} \mathrm{C}$.

The Arduino Uno is a microcontroller board based on the ATmega328. It has 20 digital input/output pins (of which 6 can be used as PWM outputs and 6 can be used as analog inputs), a $16 \mathrm{MHz}$ resonator, a USB connection, a power jack, an in-circuit system programming (ICSP) header, and a reset button. It contains everything needed to support the microcontroller; simply connect it to a computer with a USB cable or power it with a AC-to-DC adapter or battery to get started.

The Uno differs from all preceding boards in that it does not use the FTDI USB-to-serial driver chip. Instead, it features an ATmega16U2 programmed as a USB-to-serial converter. This auxiliary microcontroller has its own USB bootloader, which allows advanced users to reprogram it.

\section{METHODS}

\subsection{Required Components \\ $>$ Arduino UNO \\ $>$ MLX90614 IR Temperature Sensor \\ $>$ Servo Motor $(\mathrm{Sg} 90)$ \\ $>$ Buzzer \\ $>$ LCD 16x2 \\ $>$ Connecting Wires \\ $>$ Breadboard}

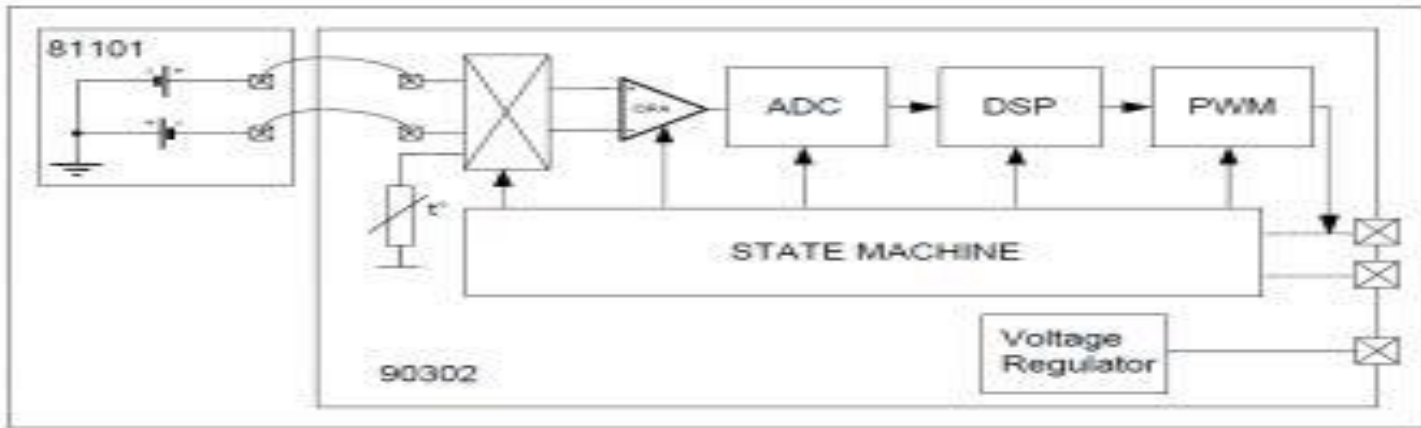

Fig. 2.1 Block Diagram of the MLX90614 Sensor 
ICRDET-2021, February 26-27, 2021, AICE, Jaipur, India

International Journal of Technical Research \& Science (Special Issue) ISSN No.:2454-2024 (online) In the below graph of the field of view (FOV) relative to the MLX90614 sensor, is reported, which is approximately equal to $35^{\circ}$. It is determined when a thermopile receives $50 \%$ of the radiation signal, and it is also related to the main axis of the sensor. Measurement accuracy is only guaranteed when the test object fully covers the field of view of the infrared sensor.

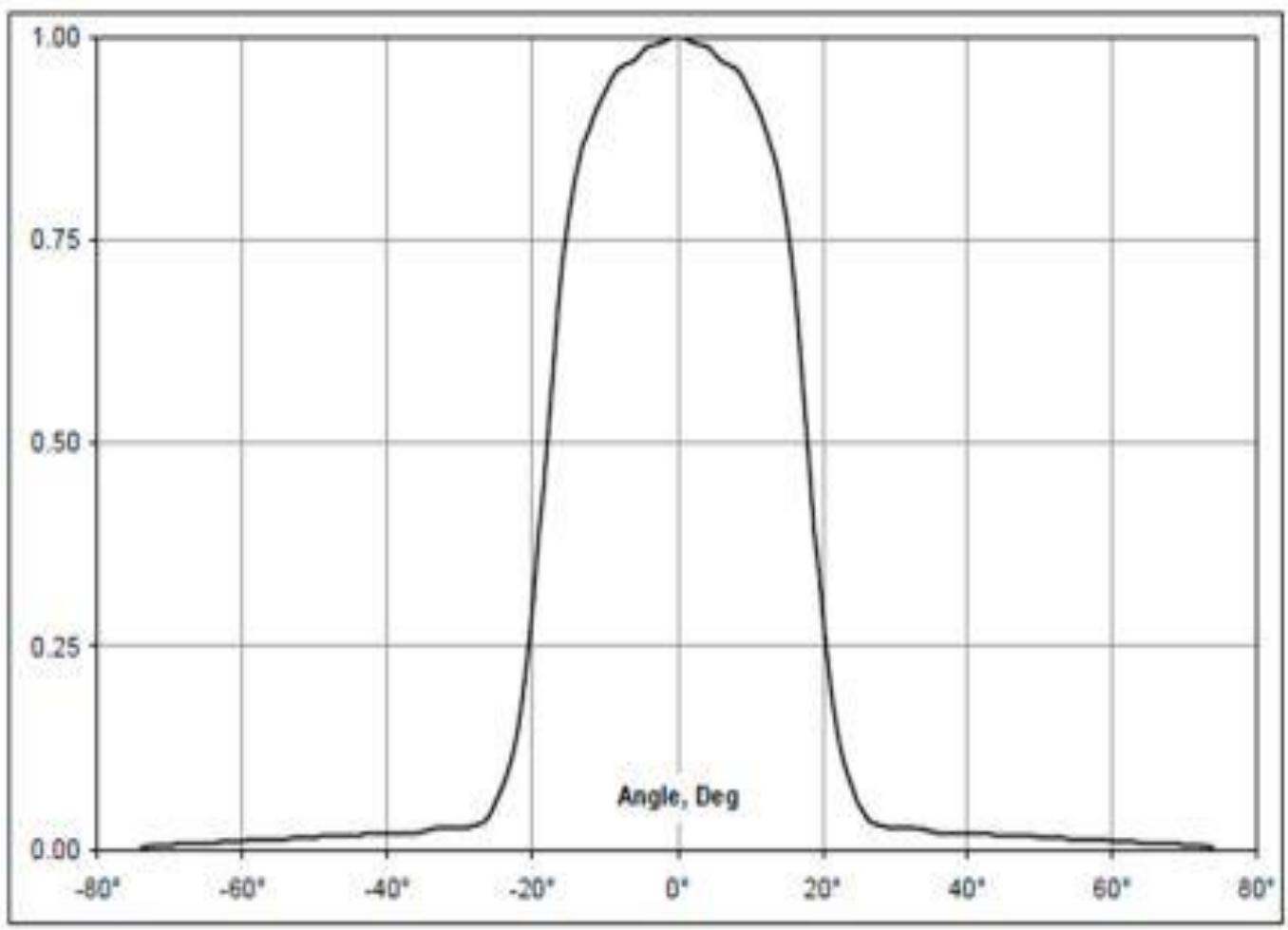

The following expression applies:

$$
\tan (\mathrm{FOV})=\frac{\text { radius of test object }}{\text { distance between infrared sensor and test object }}
$$

Displayer module can display the temperature data of the object. LCD1602 is a kind of display which can display $16 * 2$ characters with low power consumption. Pin function of LCD1602.
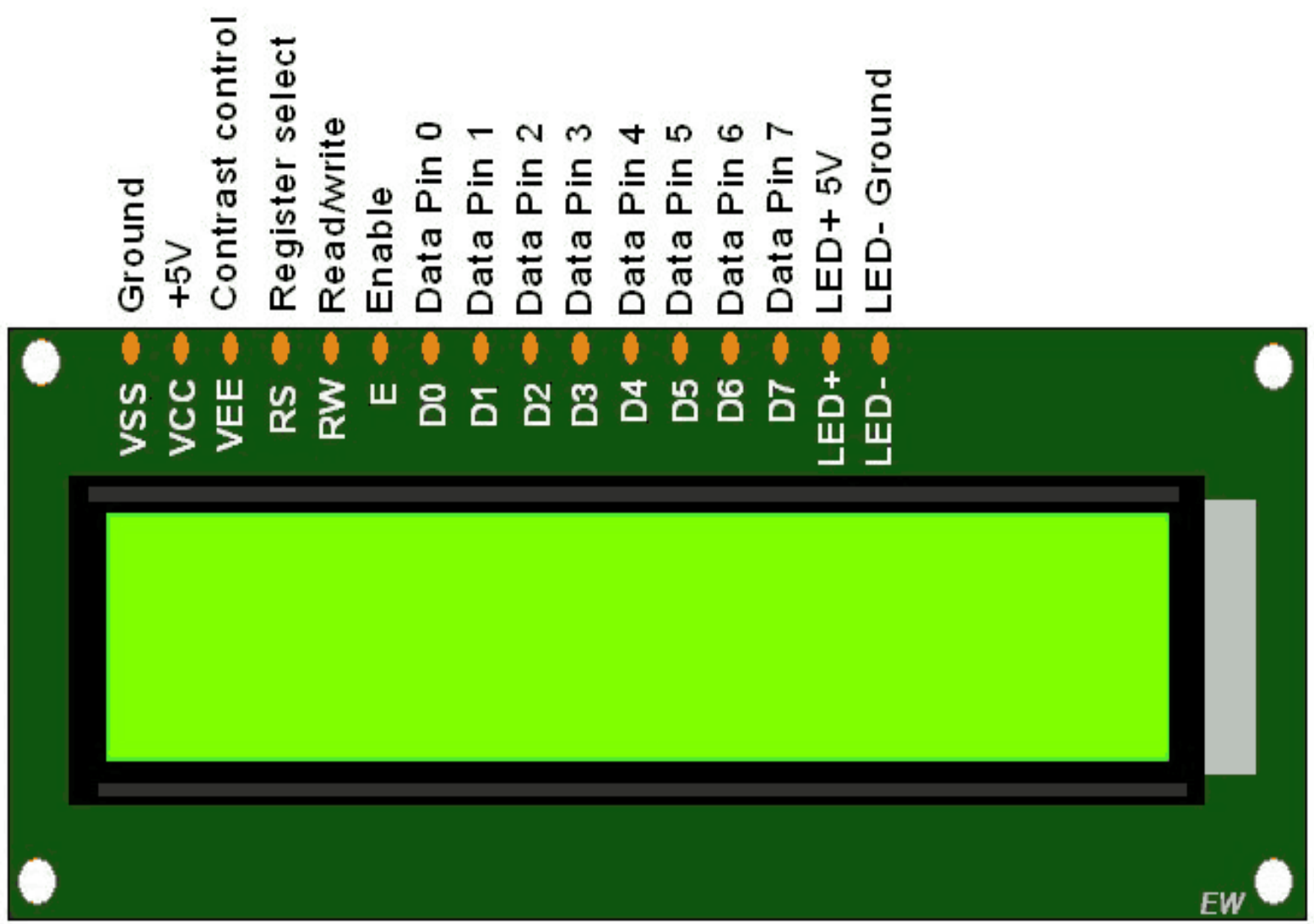

DOI Number: https://doi.org/10.30780/specialissue-ICRDET-2021/003 
ICRDET-2021, February 26-27, 2021, AICE, Jaipur, India

International Journal of Technical Research \& Science (Special Issue) ISSN No.:2454-2024 (online)

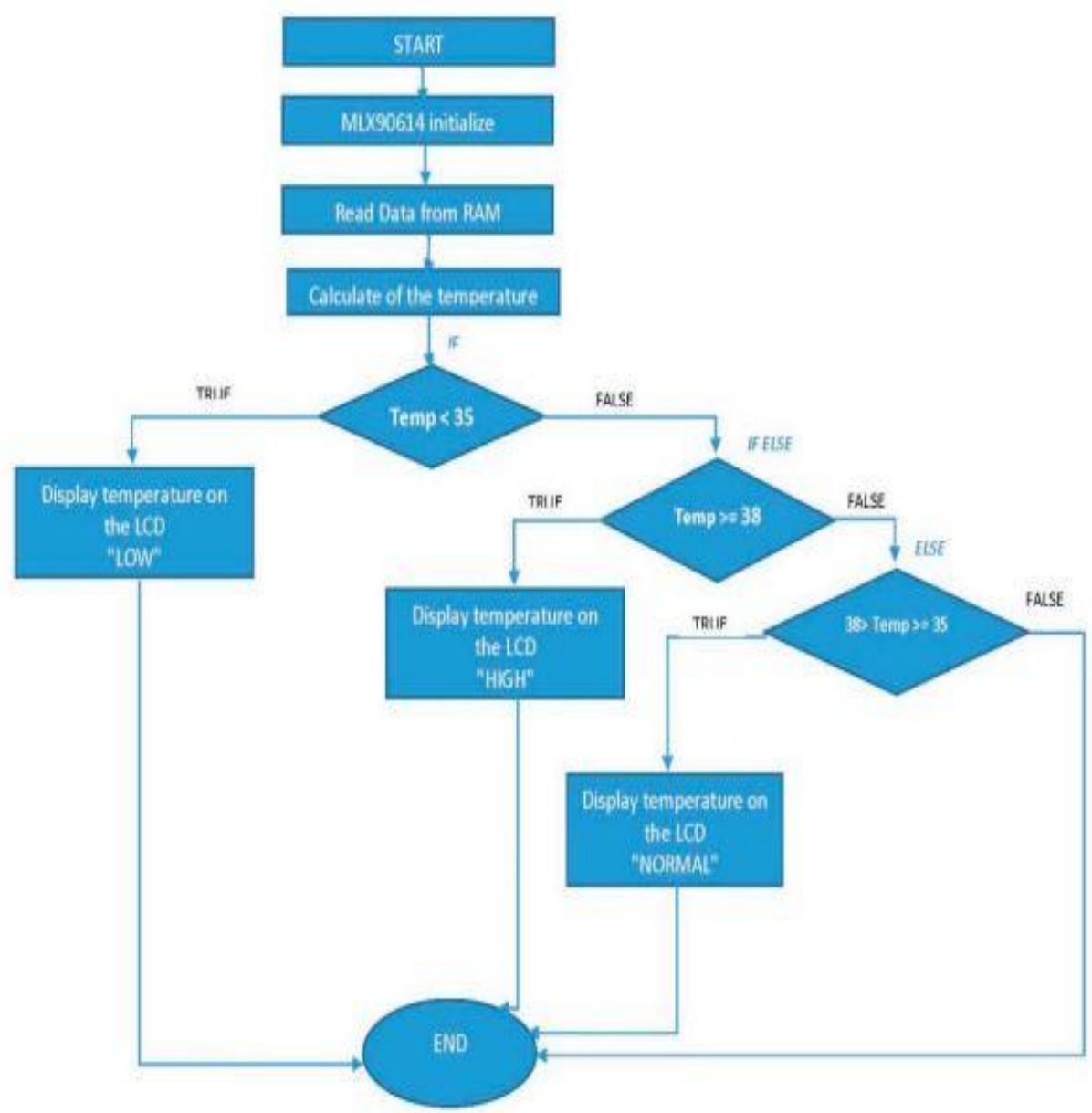

Fig. 2.2 Schematic of the algorithm for the MLX90614 Sensor

We have done simulation with the help of Tinkercad Simulator using various components i.e.

$>$ Arduino Board

$>$ Breadboard

$>$ LCD $16 \times 2$

$>$ Temp. Sensor

$>$ Buzzer

$>$ LED's

$>$ Servo Motor

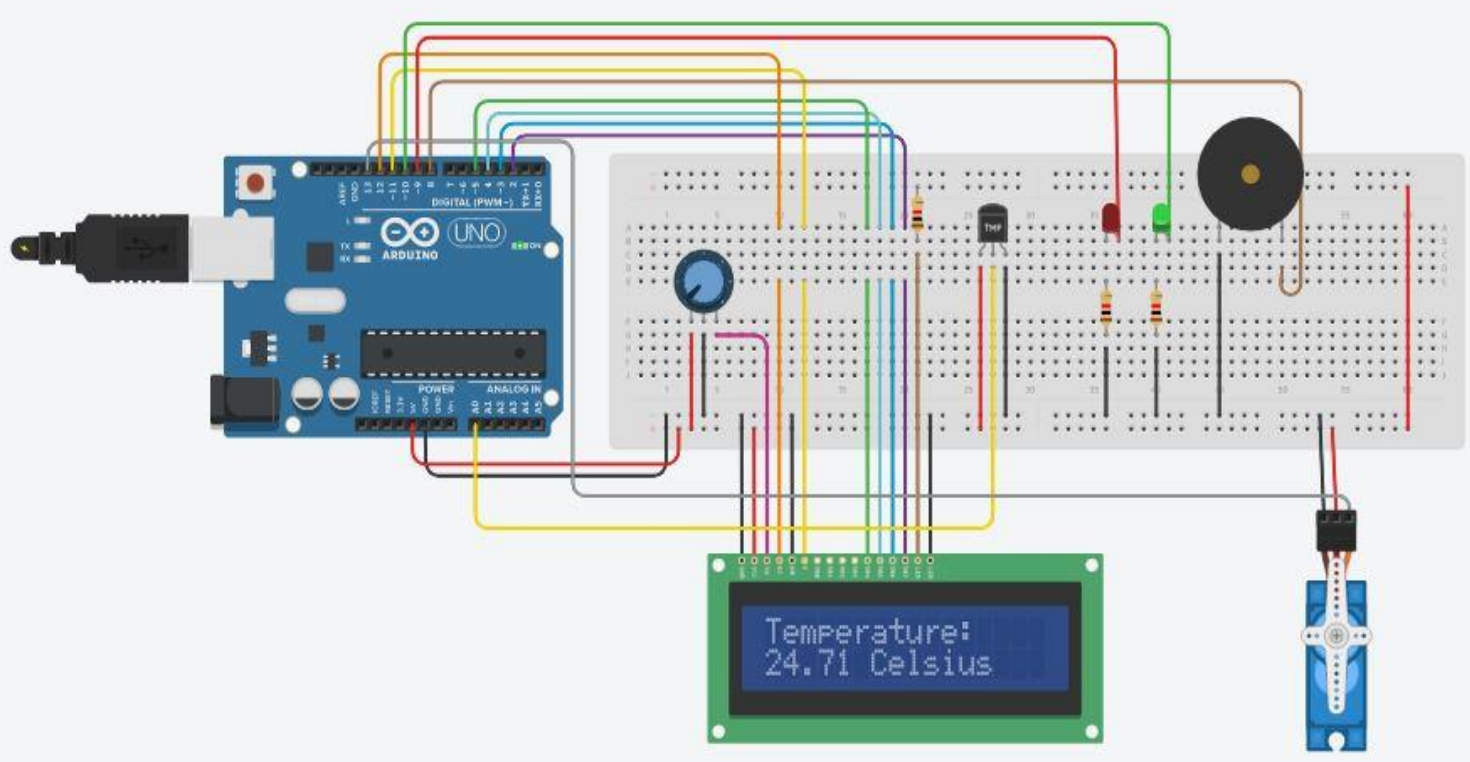

Fig. 2.3 Simulation Circuit

DOI Number: https://doi.org/10.30780/specialissue-ICRDET-2021/003 


\section{RESULTS}

Screen one person at a time, at a distance of $5 \mathrm{~cm}-10 \mathrm{~cm}$ from the sensor. It will show the body temperature of screening person on LCD. Person has normal body temperature then gate will open automatically with help of servo motor along with green led light. But person has high body temperature then gate automatically rejects the entry along with red led light and buzzer starts beeps.

\section{CONCLUSION}

This includes main arduino, temperature sensor, stepper motor and etc.With this we will know the temperature of the human being as soon as the human comes near it and we will know from it. And It will shows human body temperature under control or not. It is very useful for check the one of the most symptom of Covid-19 disease.

\section{REFERENCES}

[1] Sandra Costanzo \& Alexandra Flores “A Non-Contact Integrated Body-Ambient Temperature Sensors Platform to Contrast COVID-19” [https://www.mdpi.com/2079-9292/9/10/1658/pdf]

[2] Di Gennaro, F.; Pizzol, D.; Marotta, C.; Antunes, M.; Racalbuto, V.; Veronese, N.; Smith, L. Coronavirus Diseases (COVID-19) Current Status and Future Perspectives: A Narrative Review. Int. J. Environ. Res. Public Health 2020, 17, 2690. [CrossRef] [PubMed]

[3] Xie, J.; Zhu, Y. Association between ambient temperature and COVID-19 infection in 122 cities from China. Sci. Total Environ. 2020, 724, 1-5. [CrossRef] [PubMed]

[4] Xu, H.; Yan, C.; Fu, Q.; Xiao, K.; Yu, Y.; Han, D.; Wang, W.; Cheng, J. Possible environmental effects on the spread of COVID-19 in China. Sci. Total Environ. 2020, 731, 1-7. [CrossRef] [PubMed]

[5] Radiant Watch IoT Platform. Available online: https://radiantwatch.com/ (accessed on 5 September 2020).

[6] The Fight Against Novel Coronavirus: Automated Temperature Monitoring for COVID-19 Patients. Available online: http://www.vivalnk.com/covid-19 (accessed on 5 September 2020).

[7] Thermal Cameras Are Being Outfitted to Detect Fever and Conduct Contact Tracing for COVID-19. Available online: https://spectrum.iee.org/news-from-around-ieee/the-institute/ieee-membernews/thermal-camerasare-being-outfitted-to-detect-fever-and-conduct-contact-tracing-for-covid19 (accessed on 5 September 2020).

[8] With Safety in Phase 3 of the COVID-19 Pandemic. Available online: https://www.wikifriend.net/smarthealth-coronavirus-thermal-scanner.html (accessed on 5 September 2020).

[9] Project Idea From Arduino Project Hub

[10] Simulation Process https://www.tinkercad.com/ 